\title{
Pattern and Outcome Analysis of Orthopaedic Injuries and Fractures: A Tertiary Care Hospital-Based Study
}

\author{
Dr Subhankar Mukherjee ${ }^{1}$, Dr Partha Pratim Pal ${ }^{* 2}$, Dr Gautam Bhattacharya ${ }^{3}$, Dr Sandip Kr Roy ${ }^{4}$, Dr Rajiv Roy ${ }^{5}$, Mrs \\ Deboti Mukherjee ${ }^{6}$
}

${ }^{1}$ Assistant Professor, Department of Orthopaedics, KPC Medical College \& Hospital, 1F, Raja Subodh Chandra Mullick Road, Jadavpur, Kolkata, West Bengal 700032

${ }^{2}$ Assistant Professor, Department of Community Medicine, IPGME\&R/SSKM Hospital, 244, A.J.C. Bose Road, Bhowanipore, Kolkata, West Bengal 734012

${ }^{3}$ Professor \& Head, Department of Orthopaedics, Nil Ratan Sircar Medical College and Hospital, 138, Acharya Jagadish Chandra Bose Rd, Sealdah, Raja Bazar, Kolkata, West Bengal 700014

${ }^{4}$ Professor \& Head, Department of Orthopaedics, R. G. Kar Medical College and Hospital, 1, Khudiram Bose Sarani, Kolkata, West Bengal 700004

${ }^{5}$ Associate Professor, Department of Orthopaedics, Calcutta National Medical College and Hospital, 32, Gorachand Rd, Beniapukur, Kolkata, West Bengal 700014

${ }^{6}$ Ex-HOD, Department of Dietetics and Clinical Nutrition, Narayana Superspeciality Hospital, 120/1, Andul Rd, Near Nabanna, Shibpur, Howrah, West Bengal 711103

\begin{abstract}
Background: Management of a patient who has sustained multiple injuries requires specific and reliable methods of evaluation and treatment. The aim of the present study was to assess the functional outcomes of all traumatic (closed)fractures and how all the variables in our study affect the ultimate functional outcome. Materials \& Methods: One hundred and thirty five patients were followed up for duration of 24 weeks at 6 weekly intervals with a proper radiograph of the involved region, with requisite number of views for the assessment of fracture union during each visit. Results: The distribution of the age of the study population was, mean 32.06 (SE 1.442) years. Injury to admission interval mean is 9.56 days (SE 0.635), and injury to definitive management interval mean is 19.43days (SE0.999). Most of the fracture sustained was in the shaft of long bones of lower limbs (22.3\%) and fractures around the elbow were second most common (21.5\%). Most of the patients had no complications (51.9\%) but amongst others, stiffness was the most common complication $(21.5 \%)$. The distribution of fractures is shaft of femur, tibia and fibula is $22.3 \%$ and hind foot and proximal humerus fractures accounted for $1.5 \%$ respectively. Conclusion: Comparing the Injury to definitive management interval, Analysis of Variance (ANOVA) study showed that lesser the interval, the better the outcome and is statistically significant $(\mathrm{P}<0.05, \mathrm{~F}$ stat=20.273 $)$.Similar comparison and ANOVA study also revealed excellent outcome in mean of $6.66(95 \% \mathrm{CI})$ days of admission to injury interval and poor outcome in mean $14.45(95 \% \mathrm{CI})$ of the same.
\end{abstract}

Keywords: Orthopaedic injuries, Fractures Pattern, Outcome analysis

\section{Introduction}

The "outcomes" in orthopaedics involves careful attention to the design and statistical analysis, and appraisal of clinical research. The demarcation between "outcomes" research and "evidencebased medicine" is vague. Since the term evidence-based medicine was initially coined at McMaster University, orthopaedic surgeons and researchers have adopted a style of critical appraisal, coined as "evidence-based orthopaedics (EBO)" using a clear demarcation of relevant questions, a thorough literature search relating to the questions, an appraisal of evidence and its application to the clinical situation, and a balanced application of the results to the clinical problem. ${ }^{[1,2]}$
Poeple seeking medical attention often reaches our institution (North Bengal Medical College and Hospital) few days to several weeks and even several months after sustaining trauma. The possible factors for the unwanted delays which leads us to treat the so called neglected fractures by and large may be ignorance about the need for urgent treatment and ignorance in general, poverty, distance from the site of occurrence to the referral centre (hospital), unavailability of means of transport even during busy hours of the day, not to mention about the scenario after sundown, treatment by untrained Osteopaths (who call themselves as "Bone Setter"), Ayurved doctors, Homoeopaths and lastly by quacks on whom people rely heavily. 


\section{International Journal of Innovative Research in Medical Science (IJIRMS) \\ Volume 03 Issue 08 August 2018, ISSN: 2455-8737, Imp. Factor - 4.102 \\ Available online at - $\underline{w w w . i j i r m s . i n}$}

Management of a patient who has sustained multiple injuries requires specific and reliable methods of evaluation and treatment. The Advanced Trauma Life Support system developed by the American College of Surgeons is the most widely used method for evaluating trauma patients. Evaluation is based on the mnemonic ABCDE. ${ }^{[3]}$

According to the standard textbook of orthopaedics; the golden period for reductions and fixations of dislocations and articular fractures is said to be 6 to 9 hours. Surgical procedures can be divided into three categories: emergency, urgent, and elective. Injuries requiring emergency procedures include open fractures, irreducible dislocations of major joints, fractures with lacerations or deep excoriations in the operative field, spinal injuries with deteriorating neurological deficits, fracture-dislocations that impair the vascularity of the limb or overlying soft tissues, and fractures with compartment syndromes. In these situations, delays in surgery can lead to infection; neurological damage, amputation, and possibly death. ${ }^{[4]}$ Urgent procedures are procedures that should be done within 24 to 72 hours of injury, such as repeat debridement of severe open fractures and long bone stabilization in polytrauma patients, hip fractures, and unstable fracture-dislocations. Elective operations in trauma surgery are procedures that can be delayed 3 or 4 days to 3 or 4 weeks. Injuries that can be treated with elective surgery include isolated skeletal injuries that have been initially reduced and stabilized with nonoperative techniques but would have a better outcome with surgery, such as both-bone forearm fractures, fractures with damaged soft tissues or fracture blisters overlying the planned operative approach, and intraarticular fractures that require further radiographic evaluation for adequate preoperative planning. ${ }^{[5,6]}$

If open reductions are delayed for longer than 4 to 6 weeks, shortening of the musculotendinous units, lack of clearly defined tissue planes in the zone of injury, and resorption of the fracture surfaces make surgery more difficult. With delayed operations, autogenous bone grafting may be desirable, as in nonunion treatment. $^{[5,6,8]}$

To the best of our knowledge very few studies have been conducted so far in this region and even a thorough search for literature did not yield much study which is conducted in patients with such neglected fractures. So we are basically unaware about the outcomes which might result upon treatments of these neglected fractures. Being motivated by these untoward prevailing conditions which prevents patients from approaching our institute and refrains us from delivering the appropriate treatment in the appropriate time frame, here is an attempt with this study in (our prestigious) institute with the following aims and objectives.

\section{Aims and Objectivs}

The objectives of the study was

1. To prospectively evaluate the ultimate functional outcome of the patients who had sustained a traumatic fracture and subsequently admitted to our hospital in the Department of Orthopaedics for treatment.

2. To find out the demographic profile of the study population.
3. To find out the possible causes of delay from the institutional side in delivering early definitive intervention to the patients.

Our specific objective was to analyse the functional outcome and to what extent the patients attains pre-injury functional status.

\section{Materials and Methods}

The study was conducted in the Department of Orthopaedics, North Bengal Medical College and Hospital, on a prospective basis from June 2011 to June 2012.Out of the patients admitted in Department of Orthopaedics, NBMC\&H, since June 2011 to December 2011,135 patients were chosen according to inclusion criteria for the study and followed up for 24 weeks after they received definitive intervention. The study was conducted after getting necessary departmental permission, Institutional ethical committee permission along with informed consent from the study population.

One hundred and thirty five patients were followed up for duration of 24 weeks at 6 weekly intervals with a proper radiograph of the involved region, with requisite number of views for the assessment of fracture union during each visit. For fractures around the hip (neck femur, intertrochanteric, subtrochanteric fractures) we have used the Harris Hip Score. For shaft femur fracture, for fractures around the knee joint and both bone fractures of the leg (excluding very distal tibial fractures) we have used the Knee Society Score. ${ }^{[9]}$ Fracture around the ankle including foot fractures are assessed by The American Orthopaedic Foot and Ankle Society Score (AOFAS). ${ }^{[10]}$ All upper limb fractures are assessed using the Disabilities of Arm, Shoulder and Hand Score (Quick DASH). ${ }^{[11]}$ Range of motion of the joint concerned is measured by a goniometer.

Study Period: June 2011 to June 2012.

Study Design: Prospective case series study (level IV evidence).

Study Population: Patients attending and getting admitted from the Out Patient Department and casualty of NBMC\&H with the diagnosis of a traumatic fracture.

\section{Inclusion Criteria:}

1. All patients who sustained a traumatic fracture after confirmation of the diagnosis by relevant means like radiograph (and CT scans where needed.)

2. Patients of all age groups

3. Osteoporotic fractures

\section{Exclusion Criteria:}

Open fractures, pathological fractures; patients with any complications of fractures e.g. nonunion, infection, malunited fractures were excluded. Those cases in which there was a prospect of improvement by treatment are included and those who could not be improved by such means were excluded.

The patients fulfilling the inclusion criteria were selected alternatively twice weekly from inpatient department excluding the previously selected or enrolled bed number having same subject on next day to avoid repetition. 


\section{International Journal of Innovative Research in Medical Science (IJIRMS) \\ Volume 03 Issue 08 August 2018, ISSN: 2455-8737, Imp. Factor - 4.102}

Available online at - $\underline{w w w . i j i r m s . i n}$

For fractures around the hip (neck femur, intertrochanteric, subtrochanteric fractures) we have used the Harris Hip Score. For shaft femur fracture, and for fractures around the knee joint (supracondylar, intercondylar, patella, tibial plateau and proximal tibial metaphysis) and both bone fractures of the leg (excluding very distal tibial fractures) we have used the Knee Society Score. Fracture around the ankle including foot fractures are assessed by The American Orthopaedic Foot and Ankle Society Score (AOFAS). All upper limb fractures are assessed using the The Disabilities of Arm, Shoulder and Hand Score (Quick DASH).
Data was analyzed using SPSS (ver. 19, Chicago Inc) after entering into the MS Excel data sheet (Microsoft Corporation, USA). Descriptive statistics along with nonparametric and parametric tests were applied where necessary at $95 \%$ confidence interval considering $\mathrm{P}$ value 0.05 as level of significance.

\section{Results}

The distribution of the age of the study population was, mean 32.06 (SE 1.442) years. Injury to admission interval mean is 9.56 days (SE 0.635), and injury to definitive management interval mean is 19.43days (SE 0.999) [Table 1].

Table 1: Demographic profile of the study population

\begin{tabular}{|c|c|c|c|c|c|c|}
\hline \multirow[t]{2}{*}{ Variables } & \multirow{2}{*}{$\begin{array}{c}\mathbf{N} \\
\text { Statistic }\end{array}$} & \multirow{2}{*}{$\begin{array}{c}\text { Minimum } \\
\text { Statistic }\end{array}$} & \multirow{2}{*}{$\begin{array}{c}\text { Maximum } \\
\text { Statistic }\end{array}$} & \multicolumn{2}{|c|}{ Mean } & \multirow{2}{*}{$\begin{array}{c}\begin{array}{c}\text { Std. } \\
\text { Deviation }\end{array} \\
\text { Statistic }\end{array}$} \\
\hline & & & & Statistic & Std. Error & \\
\hline Age & 135 & 2 & 72 & 32.06 & 1.442 & 16.754 \\
\hline Injury to admission interval & 135 & 0 & 36 & 9.56 & 0.635 & 7.374 \\
\hline Injury to definitive management interval & 135 & 0 & 55 & 19.43 & 0.999 & 11.610 \\
\hline
\end{tabular}

Table 2: Frequency of fractures in males and females

\begin{tabular}{|c|c|c|}
\hline Sex & Frequency & Percentage \\
\hline Female & 43 & 68.1 \\
\hline Male & 92 & 100 \\
\hline Total & 135 & \\
\hline
\end{tabular}

The above table shows that the distribution of fractures in the study population according to sex were male $68.1 \%$ and female $31.9 \%$ respectively [Table 2].

Table 3: Frequency of fractures

\begin{tabular}{|l|c|c|}
\hline Fractures & Frequency & Percentage \\
\hline Proximal Humerus & 2 & 2.5 \\
\hline Shaft Humerus & 3 & 21.5 \\
\hline Around Elbow & 29 & 10.2 \\
\hline Forearm & 14 & 8.1 \\
\hline Around Wrist & 11 & 17.8 \\
\hline Proximal Femur & 24 & 22.3 \\
\hline Shaft femur, tibia and fibula & 30 & 10.3 \\
\hline Around Knee & 14 & 4.4 \\
\hline Around Ankle & 6 & 1.5 \\
\hline Hind foot & 2 & 100 \\
\hline Total & 135 & \\
\hline
\end{tabular}

The distribution of fractures is shaft of femur, tibia and fibula is $22.3 \%$ and hindfoot and proximal humerus fractures accounted for $1.5 \%$ respectively. Proximal humerus is, shaft humerus, fractures around elbow (which includes supracondylar humerus, intercondylar humerus, capitellum, radial head, olecranon, coronoid process of ulna), forearm (shafts of radius and ulna), Fractures around wrist (distal radius, ulna and carpal bones, proximal femur (includes intertrochanteric, neck femur and subtrochanteric fractures, shaft of femur, tibia and fibula accounts ,fractures around ankle (bimalleolar, trimalleolar, pilon, fractures around knee (patella, supracondylar femur and tibial plateau) and hindfoot (talus and calcaneus) [Table 3]. 
International Journal of Innovative Research in Medical Science (IJIRMS)

Volume 03 Issue 08 August 2018, ISSN: 2455-8737, Imp. Factor - 4.102

Available online at - $\underline{w w w . i j i r m s . i n}$

Table 4: Frequency of definitive management delivered

\begin{tabular}{|c|c|c|}
\hline TYPE OF DEFINITIVE MANAGEMENT & Frequency & Percent \\
\hline \multirow{10}{*}{$\begin{array}{l}\text { CHS } \\
\text { CR POP CAST } \\
\text { CRIF } \\
\text { CYLINDER CAST } \\
\text { EXCISSION } \\
\text { GALLOWS TRACTION } \\
\text { HEMIARTHROPLASTY } \\
\text { HIP SPICA } \\
\text { INTERLOCKING NAIL } \\
\text { JESS }\end{array}$} & 1 & .7 \\
\hline & 10 & 7.4 \\
\hline & 19 & 14.1 \\
\hline & 1 & .7 \\
\hline & 1 & .7 \\
\hline & 1 & .7 \\
\hline & 6 & 4.4 \\
\hline & 2 & 1.5 \\
\hline & 9 & 6.7 \\
\hline & 1 & .7 \\
\hline \multirow{7}{*}{$\begin{array}{l}\text { MPBG } \\
\text { ORIF } \\
\text { POP CASING } \\
\text { PROXIMAL FEMORAL NAILING } \\
\text { TENS } \\
\text { TRACTION } \\
\text { TOtal }\end{array}$} & 1 & .7 \\
\hline & 67 & 49.6 \\
\hline & 9 & 6.63 \\
\hline & 1 & .7 \\
\hline & 3 & 2.2 \\
\hline & 3 & 2.2 \\
\hline & 135 & 100.0 \\
\hline
\end{tabular}

[CHS: cannulated hip screw, CR POP CAST: closed reduction and plaster of paris cast. CRIF: closed reduction and internal fixation, EXCISSION: excision of radial head, JESS: Joshi's external stabilisation system, MPBG: muscle pedicle bone grafting ORIF: open reduction and internal fixation, POP CASING: plaster of paris casing TENS: titanium elastic nail system]

Table 5: Frequency of complications

\begin{tabular}{|l|c|c|}
\hline Complications & Frequency & \multicolumn{2}{|c|}{ Percentage } \\
\hline Delayed Union & 1 & 0.7 \\
\hline Limp & 1 & 0.7 \\
\hline Malunion and Shortening & 3 & 5.2 \\
\hline None & 70 & 3.9 \\
\hline Osteomyelitis & 4 & 4.0 \\
\hline Pain & 6 & 8.1 \\
\hline Pain And Stiffness & 11 & 7.4 \\
\hline Painful Limp & 10 & 21.5 \\
\hline Stiffness & & 100 \\
\hline Total & 29 & \\
\hline
\end{tabular}

Most of the patients had no complications (51.9\%) but amongst others, stiffness was the most common complication (21.5\%) [Table 5].

Table 6: Frequency of outcomes

\begin{tabular}{|l|c|c|}
\hline Outcome & Frequency & Percentage \\
\hline Excellent & 38 & 28.1 \\
\hline Fair & 28 & 20.7 \\
\hline Good & 18 & 30.4 \\
\hline Poor & 41 & 7.4 \\
\hline Satisfactory & 10 & 100 \\
\hline Total & 135 & \\
\hline
\end{tabular}

Above table shows that the outcome measure was poor in $30.4 \%$ and satisfactory in $7.4 \%$ respectively [Table 6].

Table 7: Association between outcome measures and injury to management interval

\begin{tabular}{|l|l|c|c|}
\hline Dependant Variable & Outcomes & $\mathrm{N}$ & Mean/SE/CI \\
\hline \multirow{4}{*}{ Injury-Management Interval } & Excellent & 38 & $12.66 / 0.985 /[10.66-14.65]$ \\
\cline { 2 - 4 } & Good & 18 & $15.00 / 2.647 /[9.42-20.58]$ \\
\cline { 2 - 4 } & Satisfactory & 10 & $8.80 / 2.394 /[3.39-14.21]$ \\
\cline { 2 - 4 } & Fair & 28 & $21.57 / 2.062 /[17.34-25.80]$ \\
\cline { 2 - 4 } & Poor & 41 & $28.78 / 1.540 /[25.67-31.89]$ \\
\cline { 2 - 4 } & Total & 135 & $19.43 / 0.999 /[17.45-21.41]$ \\
\hline
\end{tabular}

Table 7 shows that the mean difference of injury management interval according to outcome are statistically significant $p=0.000(P<0.05, F$ stat $=20.273$ ) 
International Journal of Innovative Research in Medical Science (IJIRMS)

Volume 03 Issue 08 August 2018, ISSN: 2455-8737, Imp. Factor - 4.102

Available online at - $\underline{w w w . i j i r m s . i n}$

Table 8: Association between admission to injury interval and outcome

\begin{tabular}{|l|l|c|c|}
\hline Dependant Variable & Outcomes & $\mathrm{N}$ & Mean/SE/CI \\
\hline \multirow{4}{*}{ Admission Injury Interval } & Excellent & 38 & $6.66 / 0.751[5.14-8.18]$ \\
\cline { 2 - 4 } & Good & 18 & $5.83 / 1.471[2.73-8.94]$ \\
\cline { 2 - 4 } & Satisfactory & 10 & $6.00 / 1.820[1.88-10.12]$ \\
\cline { 2 - 4 } & Fair & 28 & $9.96 / 1.485[6.92-13.01]$ \\
\cline { 2 - 4 } & Poor & 41 & $14.46 / 1.153[12.13-16.79]$ \\
\cline { 2 - 4 } & Total & 135 & $9.56 / 0.635[8.3-10.81]$ \\
\hline
\end{tabular}

Above table 8 reveals excellent outcome in mean of 6.66 (95\% CI) days of admission to injury interval and poor outcome in mean 14.45 (95\% CI) days of the same, which is statistically significant $p=0.000(p=<0.05$ and $F$ stat $=9.791)$.

Table 9: Multiple comparisons association between injury management intervals and outcomes

\begin{tabular}{|c|c|c|c|c|c|c|c|}
\hline \multirow{2}{*}{$\begin{array}{c}\text { Dependent } \\
\text { Variable }\end{array}$} & \multirow{2}{*}{ (I) remark } & \multirow{2}{*}{ (J) remark } & \multirow{2}{*}{ Mean Difference (I -J) } & \multirow{2}{*}{ Std. Error } & \multirow{2}{*}{ Sig. } & \multicolumn{2}{|c|}{ Sig. 95\% Confidence Interval } \\
\hline & & & & & & Lower Bound & Upper Bound \\
\hline \multirow{16}{*}{$\begin{array}{l}\text { Injury } \\
\text { management } \\
\text { interval }\end{array}$} & \multirow[t]{4}{*}{ Excellent } & Good & 2.342 & 2.647 & 1.000 & -9.90 & -5.22 \\
\hline & & Satisfactory & 3.858 & 3.288 & 1.000 & -5.53 & 13.25 \\
\hline & & Fair & $-8.914 *$ & 2.304 & 0.002 & -15.49 & -2.33 \\
\hline & & Poor & $-16.123^{*}$ & 2.083 & 0.000 & -22.07 & -10.17 \\
\hline & \multirow[t]{4}{*}{ Good } & Excellent & 2.342 & 2.647 & 1.000 & -5.22 & 9.90 \\
\hline & & Satisfactory & 6.200 & 3.648 & 0.916 & -4.22 & 16.62 \\
\hline & & Fair & -6.571 & 2.795 & 0.202 & -14.55 & 1.41 \\
\hline & & Poor & $13.780 *$ & 2.616 & 0.000 & -21.25 & -6.31 \\
\hline & \multirow[t]{4}{*}{ Satisfactory } & Excellent & -3.858 & 3.288 & 1.000 & -13.25 & 5.53 \\
\hline & & Good & -6.200 & 3.648 & 0.916 & -16.62 & 4.22 \\
\hline & & Fair & $-12.771 *$ & 3.408 & 0.003 & -22.50 & -3.04 \\
\hline & & Poor & $-19.980^{*}$ & 3.263 & 0.000 & -29.30 & -10.66 \\
\hline & \multirow[t]{4}{*}{ Fair } & Excellent & $8.914 *$ & 2.304 & 0.002 & 2.33 & 15.49 \\
\hline & & Good & 6.571 & 2.795 & 0.202 & -1.41 & 14.55 \\
\hline & & Satisfactory & $12.771 *$ & 3.408 & 0.003 & 3.04 & 22.50 \\
\hline & & Poor & $-7.209 *$ & 2.268 & 0.018 & -13.69 & -0.73 \\
\hline & \multirow[t]{4}{*}{ Poor } & Excellent & $16.123 *$ & 2.083 & 0.000 & 10.17 & 22.07 \\
\hline & & Good & $13.780 *$ & 2.616 & 0.000 & 6.31 & 21.25 \\
\hline & & Satisfactory & $19.980 *$ & 3.263 & 0.000 & 10.66 & 29.30 \\
\hline & & Fair & $7.209 *$ & 2.268 & 0.018 & 0.73 & 13.69 \\
\hline
\end{tabular}

[*The mean difference is significant at the 0.05 level.]

Above table 9 shows that the mean difference from excellent outcome to poor outcome with regard to the injury to definitive management intervals are statistically significantly $\mathrm{P}=0.000(95 \% \mathrm{CI})$.

Table 10: Multiple comparisons association between admission injury intervals and outcomes

\begin{tabular}{|c|c|c|c|c|c|c|c|}
\hline \multirow{2}{*}{$\begin{array}{l}\text { Dependent } \\
\text { Variable }\end{array}$} & \multirow{2}{*}{ (I) remark } & \multirow{2}{*}{ (J) remark } & \multirow{2}{*}{ Mean Difference (I -J) } & \multirow{2}{*}{ Std. Error } & \multirow{2}{*}{ Sig. } & \multicolumn{2}{|c|}{ Sig. 95\% Confidence Interval } \\
\hline & & & & & & Lower Bound & Upper Bound \\
\hline \multirow{16}{*}{$\begin{array}{l}\text { Admission injury } \\
\text { interval }\end{array}$} & \multirow[t]{4}{*}{ Excellent } & Good & 0.825 & 1.878 & 1.000 & -4.54 & 6.19 \\
\hline & & Satisfactory & .658 & 2.333 & 1.000 & -6.00 & 7.32 \\
\hline & & Fair & -3.306 & 1.635 & .452 & -7.97 & 1.36 \\
\hline & & Poor & $7.806^{*}$ & 1.478 & .000 & -12.03 & -3.58 \\
\hline & \multirow[t]{4}{*}{ Good } & Excellent & -0.825 & 1.878 & 1.000 & -6.19 & 4.54 \\
\hline & & Satisfactory & -0.167 & 2.589 & 1.000 & -7.56 & 7.23 \\
\hline & & Fair & -4.131 & 1.983 & 0.392 & -9.79 & 1.53 \\
\hline & & Poor & $-8.630^{*}$ & 1.856 & 0.000 & -13.93 & -3.33 \\
\hline & \multirow[t]{4}{*}{ Satisfactory } & Excellent & -0.658 & 2.333 & 1.000 & -7.32 & 6.00 \\
\hline & & Good & 0.167 & 2.589 & 1.000 & -7.23 & 7.56 \\
\hline & & Fair & -3.964 & 2.418 & 1.000 & -10.87 & 2.94 \\
\hline & & Poor & $-8.463 *$ & 2.315 & 0.004 & -15.07 & -1.85 \\
\hline & \multirow[t]{4}{*}{ Fair } & Excellent & 3.306 & 1.635 & 0.452 & -1.36 & 7.97 \\
\hline & & Good & 4.131 & 1.983 & 0.392 & -1.53 & 9.79 \\
\hline & & Satisfactory & 3.964 & 2.418 & 1.000 & -2.94 & 10.87 \\
\hline & & Poor & -4.499 & 1.609 & .060 & -9.09 & 0.10 \\
\hline
\end{tabular}


International Journal of Innovative Research in Medical Science (IJIRMS)

Volume 03 Issue 08 August 2018, ISSN: 2455-8737, Imp. Factor - 4.102

Available online at - $\underline{w w w . i j i r m s . i n}$

\begin{tabular}{|l|l|l|c|c|c|c|c|}
\hline \multirow{3}{*}{ Poor } & Excellent & $7.806^{*}$ & 1.478 & 0.000 & 3.58 & 12.03 \\
\cline { 3 - 9 } & & Good & $8.630^{*}$ & 1.856 & 0.000 & 3.33 & 13.93 \\
\cline { 2 - 9 } & Satisfactory & $8.463^{*}$ & 2.315 & .004 & 1.85 & 15.07 \\
\cline { 2 - 9 } & & 4.499 & 1.609 & 0.060 & -0.10 & 9.09 \\
\hline
\end{tabular}

[*The mean difference is significant at the 0.05 level.]

Above table 10 shows that the mean difference between excellent outcome and poor outcome with regard to the injury to admission interval is statistically significant $\mathrm{P}=0.000(95 \% \mathrm{CI})$.

Table 11: Outcomes related to first contact physicians

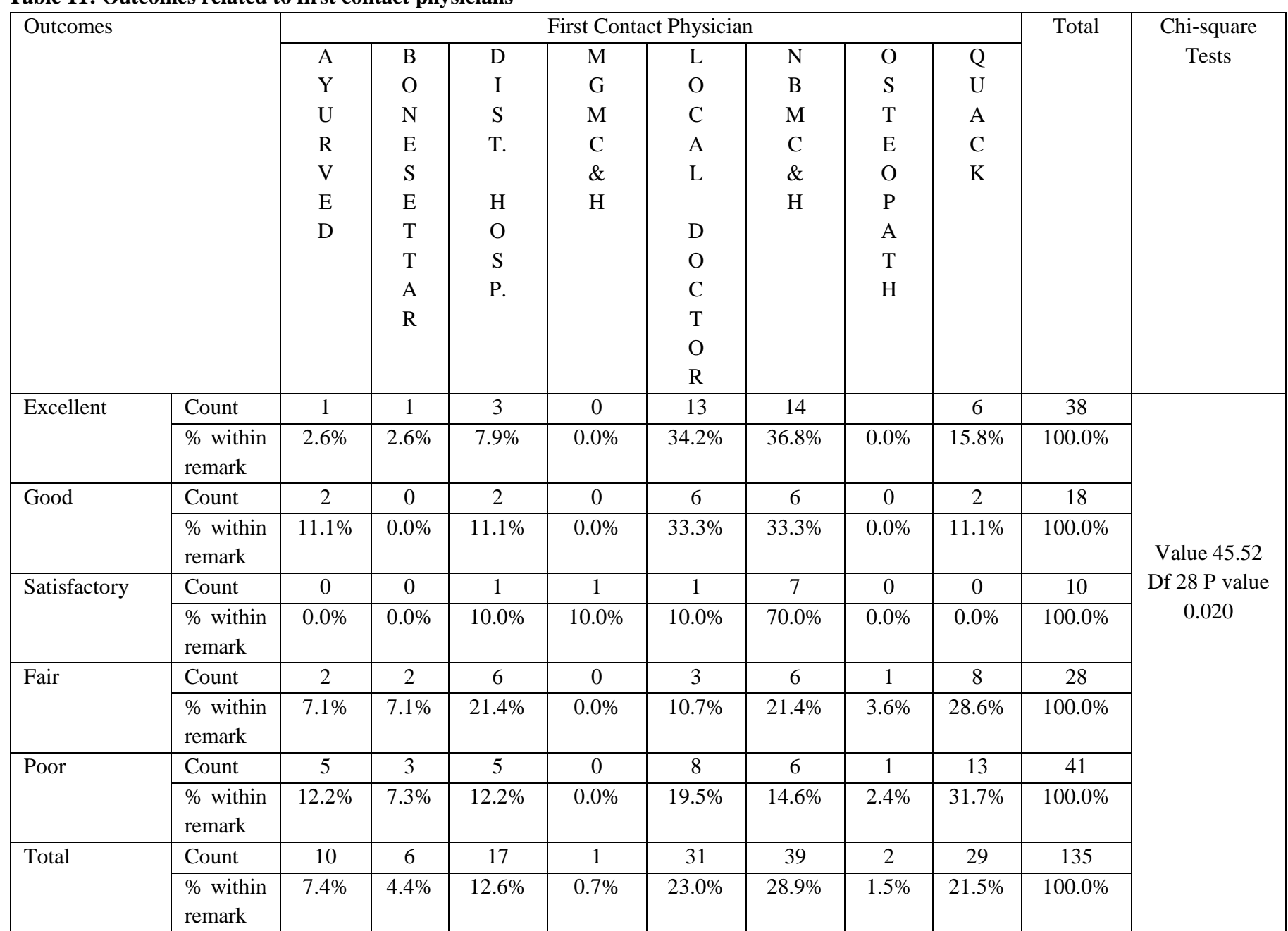

Above table 11 shows that patients who went to Quacks had a poor outcome (31.7\%) whereas those who attended NBMC\&H had (36.8\%) excellent outcome and the differences are statistically significant $(\mathrm{X} 2=45.52, \mathrm{df}=28 \mathrm{P}<0.05)$.

\section{Discussion}

In the present study, the age distribution in the study population was, mean 32.06 (SE 1.442) years and the sex distribution of the study population shows that $31.9 \%$ of the fracture patients were female and $68.1 \%$ were males respectively. Südkamp NP et al ${ }^{[12]}$ did not find any significant correlation between age and sex and functional outcome of proximal humeral fracture. Eisler $\mathbf{J}$ et al ${ }^{[13]}$ in their prospective study of undisplaced femoral neck fractures in 70 patients with mean age of 70 years treated by cannulated hip screws and followed up showed that age did not affect the ultimate functional outcome.

The mean injury to admission interval was 9.56 (SE 0.635) days and mean injury to definitive management interval was 19.43(SE 0.999) days. Considering injury-definitive management interval, those with a mean interval of 12.66 days $(95 \% \mathrm{CI})$ had excellent outcome, those with mean of 15 days had good outcome, those with 8.80 (SE 2.394) had satisfactory outcome, mean delay of 21.57 days had fair and 28.78 days interval had poor outcome $(\mathrm{p}=0.000)$. In the present study, outcome was poor when the admission to Injury interval was mean 14.46 days $(95 \% \mathrm{CI})$ and excellent when the same was 6.66 days $(95 \% \mathrm{CI})$, good outcome resulted when mean delay was 5.83 days, satisfactory when it was 6 days, fair in mean 9.96 days delay $(\mathrm{p}=0.000$ i.e. statistically significant). The mean difference in days between excellent outcome and poor outcome with regard to the admission-injury interval is significant $\mathrm{p}=0.000(95 \% \mathrm{CI})$.

Amongst complications pain with stiffness, and stiffness alone were very common ( $21.5 \%$ and $8.1 \%$ respectively) at the end of 24 weeks follow up and is due to delay either at presentation or in delivering definitive treatment, $51.9 \%$ of patients had no complications because either they received early definitive fixation 


\section{International Journal of Innovative Research in Medical Science (IJIRMS) \\ Volume 03 Issue 08 August 2018, ISSN: 2455-8737, Imp. Factor - 4.102}

Available online at - $\underline{w w w . i j i r m s . i n}$

in the emergency operation theatre or due to early presentation to us. For similar reasons excellent functional outcome was seen in $28.1 \%$ cases ,fair in $20.7 \%$, good in $13,3 \%$,satisfactory in $7.4 \%$, and poor in $30.4 \%$ cases.

Delayed union and limp were present in $0.7 \%$ respectively, malunion and shortening in $2.2 \%$,post operative osteomyelitis in $3 \%$,pain and painful limp in $4.4 \%$ and $7.4 \%$ respectively. These complications were in part due to the delay at presentation to us and various factors contributing to it and for those who presented to us in time but for the infrastructural limitations we were unable to deliver definitive treatment, which led into the conversion of a fresh fracture into a neglected fracture. ${ }^{[14]}$ For example Jain et al ${ }^{[15]}$ compared early fixation (within 12 hours of injury) to delayed fixation(more than 12 hours) of femoral neck fracture with cannulated hip screws and recorded an incidence of avascular necrosis in $16 \%$ of the delayed group compared with none in the early fixation group. In our scenario we were able to deliver definitive fixation, but not anywhere before two weeks from the date of admission thus increasing complication rates such as nonunion, avascular necrosis and fixation failure.

Intraarticular fractures should be fixed within 48 to 72 hours, if this is delayed for 2 to 3 weeks, for any reason like the general condition of the patient precluding anaesthetic fitness or other medical issues, results are seldom good with increased rates of complications like stiffness, increased risk of heterotopic ossification and thus resulting in worse outcomes. ${ }^{[16,17]}$

We also found that the mean difference from excellent outcome to poor outcome with regard to the injury to definitive management intervals is statistically significantly, $\mathrm{P}=0.000$ (95\% CI), and similarly that the mean difference between excellent outcome and poor outcome with regard to the injury to admission interval is also statistically significant $\mathrm{P}=0.000(95 \% \mathrm{CI})$.

Other factors which seriously affect the functional outcome, apart from the ones mentioned above (also known as the confounders) are the personality and site of fracture (i.e. periarticular, articular or diaphyseal), the latter having far better outcome, comminuted (which are generally the result of high velocity trauma lest the bone is osteoporotic) vs transverse or spiral which are generally low velocity. Hung et $\mathrm{al}^{[18]}$ in their study to clarify factors affecting outcome of type II floating knee showed that that Intra-articular knee involvement is the most important factor contributing to poor outcome of type II floating knee $(\mathrm{p}=0.013)$. Fractures involving complex joints as for example wrist and ankle generally has a dismal outcome. Belchar et $\mathrm{al}^{[19]}$ in their study of 40 malleolar fractures fixed with open reduction and internal fixation and reviewed 8-24 months showed significant impaired function.

The choice of implant for example plate vs locking nail in case of long bone diaphyseal fractures of lower limbs plays a significant role in outcome as early weight bearing is possible in case of locking nail. ${ }^{[20,21]}$ Fixation techniques is also of paramount importance in affecting outcome, i.e. whether standard AO/ASIF techniques are followed by the surgeon or not. ${ }^{[22]}$ The training of the surgeon, level of expertise, duration of the operation, per operative blood loss, general condition of the patient, diabetic status, whether smoker or not, preoperative comorbidities like cardiorespiratory compromise, renal compromisation also plays a vital role in the ultimate outcome. ${ }^{[23]}$ All these above mentioned parameters cannot be studied in our study. Moreover the limitation of our study is fewer numbers of cases and lack of blinding. We feel that a study which includes all these above mentioned factors should be conducted in our region to add further to the existing knowledge.

\section{Conclusion}

Comparing the Injury to definitive management interval, Analysis of Variance (ANOVA) study showed that lesser the interval, the better the outcome and is statistically significant $(\mathrm{P}<0.05, \mathrm{~F}$ stat=20.273).Similar comparison and ANOVA study also revealed excellent outcome in mean of $6.66(95 \% \mathrm{CI})$ days of admission to injury interval and poor outcome in mean $14.45(95 \% \mathrm{CI})$ of the same, which is statistically significant $(\mathrm{p}=<0.05$ and $\mathrm{F}$ stat=9.791), when comparing injury to admission interval in days. Majority of the patients (51.9\%) had no complications and these are the ones who received their definitive management in the emergency operation theatre within 3 to 5 days of their injury but amongst the rest, stiffness $(21.5 \%)$ of the related joint was the most frequent complication. Poor outcome was most common (30.4\%) and satisfactory in $7.4 \%$, but excellent, fair and good was seen in $28.1 \%, 20.7 \%$ and $13.3 \%$ respectively.

We are being driven by circumstances to perform an operation (due to various before mentioned reasons) that finds no place in the standard texts of latest editions. We do not have the state of the art diagnostic facilities like intraoperative cultures, frozen section analysis for histopathology not to mention about the availability of PCR and others. We have to solely rely upon strict asepsis of surgeons and parenteral antibiotics from our part to prevent infections. Apart from these confounders there are others such as the personality of the fracture, site of the fracture, other systemic effects of trauma such as malnutrition, pulmonary and gastrointestinal dysfunction, immunologic and neurological injury, preoperative co-morbidities like cardio-respiratory and renal compromise, age and general condition of the patient, i.e. whether the patient is diabetic or hypertensive or smoker. Timing and duration of the surgery, per operative blood loss, training and expertise of the operating surgeon, soft tissue handling, reduction techniques employed and choice of the implants are amongst them.

\section{References}

[1] Outcomes Research. Fact Sheet. AHRQ Publication No. 00-P011, March 2000. Agency for Healthcare Research and Quality, Rockville, MD. Available at https://archive.ahrq.gov/research/findings/factsheets/outc omes/outfact/outcomes-and-research.html [Accessed on 31 March 2018]

[2] Guyatt GH. Evidence-based medicine. Am Coll Phys J Club 1991; 114:A16.

[3] American College of Surgeons Committee on Trauma, 1985. American College of Surgeons Committee on Trauma: Advanced trauma life support courses, Chicago, Ill, American College of Surgeons, 1985.

[4] Bone LB, Johnson KD, Weigelt J, Scheinberg R. Early versus delayed stabilization of femoral fractures. A prospective randomized study. J Bone Joint Surg Am. 1989 Mar; 71(3):336-40. 
[5] Chapman MW. Fractures of the pelvic ring and acetabulum in patients with severe polytrauma. Instr Course Lect. 1990; 39:591-3.

[6] Gossling HR, Donohue TA. The fat embolism syndrome. JAMA 1979; 241:2740-2742.

[7] Pallister I, Empson K. The effects of surgical fracture fixation on the systemic inflammatory response to major trauma. J Am Acad Orthop Surg. 2005 Mar-Apr; 13(2):93-100.

[8] Kloen P, Buijze GA, Ring D. Management of forearm nonunions: current concepts. Strategies in Trauma and Limb Reconstruction. 2012; 7(1):1-11.

[9] Insall JN, Dorr LD, Scott RD, Scott WN. Rationale of the Knee Society clinical rating system. Clin Orthop Relat Res. 1989 Nov; (248):13-4.

[10] Van Lieshout EMM, De Boer AS, Meuffels DE, et al. American Orthopaedic Foot and Ankle Society (AOFAS) Ankle-Hindfoot Score: a study protocol for the translation and validation of the Dutch language version. BMJ Open 2017; 7: e012884.

[11] Hudak PL, Amadio PC, Bombardier C. Development of an upper extremity outcome measure: the DASH (disabilities of the arm, shoulder and hand) [corrected]. The Upper Extremity Collaborative Group (UECG) Am J Ind Med. 1996 Jun; 29(6):602-8. Erratum in: Am J Ind Med 1996 Sep; 30(3):372.

[12] Südkamp NP, Audigé L, Lambert S, Hertel R, Konrad G. Path analysis of factors for functional outcome at one year in 463 proximal humeral fractures: J Shoulder Elbow Surg. 2011 Dec;20(8):1207-16. Epub 2011 Sep 14.

[13] Eisler J, Cornwall R, Strauss E, Koval K, Siu A, Gilbert M. Outcomes of elderly patients with nondisplaced femoral neck fractures: Clin Orthop Relat Res. 2002 Jun;(399):52-8.

[14] Roshan A, Ram S. The Neglected Femoral Neck Fracture in Young Adults: Review of a Challenging Problem. Clinical Medicine \& Research. 2008; 6(1):33-39.

[15] Jain R, Koo M, Kreder HJ, Schemitsch EH, Davey JR, Mahomed NN. Comparison of early and delayed fixation of subcapital hip fractures in patients sixty years of age or less. J Bone Joint Surg Am. 2002; 84-A (9):16051612.

[16] Manninger J, Kazar G, Fekete G, et al. Significance of urgent (within 6h) internal fixation in the management of fractures of the neck of the femur. Injury. 1989; 20(2):101-105.

[17] Razik F, Alexopoulos AS, El-Osta B, Connolly MJ, Brown A, Hassan S et al. Time to internal fixation of femoral neck fractures in patients under sixty years-does this matter in the development of osteonecrosis of femoral head? Int Orthop. 2012; 36:2127-2132.

[18] Hung SH, Lu YM, Huang HT, Lin YK, Chang JK, Chen JC, et al. Surgical treatment of type II floating knee: comparisons of the results of type IIA and type IIB floating knee: Knee Surg Sports Traumatol Arthrosc. 2007 May; 15(5):578-86. Epub 2007 Jan 4.

[19] Belcher GL, Radomisli TE, Abate JA, Stabile LA, Trafton PG.Functional outcome analysis of operatively treated malleolar fractures: J Orthop Trauma. 1997 FebMar; 11(2):106-1.
[20] Omerovic D, Lazovic F, Hadzimehmedagic A. Static or Dynamic Intramedullary Nailing of Femur and Tibia. Medical Archives. 2015; 69(2):110-113.

[21] Mukherjee S, Arambam MS, Waikhom S, Santosha, Masatwar PV, Maske RG. Interlocking Nailing Versus Plating in Tibial Shaft Fractures in Adults: A Comparative Study. Journal of Clinical and Diagnostic Research : JCDR. 2017; 11(4):RC08-RC13.

[22] McKenna PB, O'Shea K, Burke T. Less is more: lag screw only fixation of lateral malleolar fractures. International Orthopaedics. 2007; 31(4):497-502.

[23] Zambouri A. Preoperative evaluation and preparation for anesthesia and surgery. Hippokratia. 2007; 11(1):13-21.

\section{*Corresponding Author:}

Dr. Partha Pratim Pal

Postal Address: Assistant Professor, Department of Community Medicine, IPGME\&R/SSKM Hospital, 244, A.J.C. Bose Road, Bhowanipore, Kolkata, West Bengal 734012

Email: parthapal2p3 [at] gmail.com 